have occurred. In fact, artificial insemination would have been an unfortunate mistake in the one couple in whom it was considered during their treatment for secondary infertility.

There is clear evidence that apparently complete restoration of reproductive function can occur if chronic renal failure is completely reversed by successful renal transplantation. Hume et al. (1966) described proved fertility in a man and successful pregnancy in a woman, both of whom were being treated with long-term immunosuppressive therapy following renal transplantation. Though maintenance dialysis is only an incomplete substitute for normal renal function, it can be remarkably effective in avoiding or reversing the complications of prolonged uraemia. In men it certainly does not influence fertility; whereas in women the picture is more complicated, since the severe anaemia, which cannot be corrected by dialysis, would make the continuation of a pregnancy hazardous. Nevertheless, women on dialysis may be fertile, and ovulation has occurred in women on such treatment (Goodwin et al., 1968. This matches our own experience in that normal menstruation has returned in several patients soon after starting maintenance dialysis, and this has led us to advise contraceptive precautions in those of our female patients who might be at risk. Because of the possible side-effects of oral contraceptives, which include a risk of clotting the arteriovenous shunt and poor control of hypertension, we have recommended the use of mechanical methods of contraception such as a sheath or diaphragm with a spermicidal jelly.

Among our 10 male patients having sexual intercourse with no contraceptive precautions the three resulting pregnancies are perhaps a better index of fertility than the results of semen analysis. In a healthy population over a similar time period one would expect to see about twice the fertility rate we saw in these 10 patients (Tietze, 1962 ; Barton, 1968).

We wish to thank Dr. C. P. Farthing and Dr. N. Peele for carrying out the semen analyses and Professor H. E. de Wardener and Professor N. Morris for their help in reviewing the manuscript. Dr. R. A. Zeitlin kindly carried out the blood group studies in the South London Blood Transfusion Centre, Sutton, Surrey.

REFERENCES

Barton, M. (1968). Fournal of Reproduction and Fertility, 16, 327.

Curtis, J. R., et al. (1969). Quarterly foumal of Medicine, 38, 49.

Goodey, J., and Kelly, J. (1967). Lancet, 2, 147.

Goodwin, N. J., Valenti, C., Hall, J. E., and Friedman, E. A. (1968). American fournal of Obstetrics and Gynecology, 100, 528.

Hume, D. M., et al. (1966). Annals of Surgery, 164, 352.

Oken D E (1966). American fournal of Obstetrics and Gynecology,

94, 1023.
Schreiner, G. E., and Maher, J. F. (1965). Annals of Internal Medicine, 62, 551 .

Sokol, 6 . (1967). Transactions. American Society for Artificial Internal Organs, 13, 51

Tietze, C. (1962). Population Studies, 16, 31.

\title{
Effect of Diazepam on Awareness during Caesarean Section Under General Anaesthesia
}

\author{
DAVID J. TURNER, $†$ M.B., F.F.A. R.C.S., D.A. ; JAMES WILSON,* M.B., F.F.A. R.C.S., D.OBST.R.C.O.G.
}

\begin{abstract}
Summary: The use of diazepam for premedication $S$ before elective caesarean section increased the incidence of unpleasant recall postoperatively, compared with atropine in a previous study. This finding suggests that diazepam is unsuitable for this type of anaesthesia.
\end{abstract}

\section{Introduction}

In our previous investigation of awareness during caesarean section under general anaesthesia (Wilson and Turner, 1969) it was shown that the administration of a narcotic within six hours of operation significantly reduced the incidence of unpleasant recall (recall of awareness during operation, of pain, or of unpleasant dreaming during anaesthesia). As it would appear to be unjustifiable to give a narcotic premedicant routinely before elective section we had hoped to show a similar effect (reduction in unpleasant recall) with the benzdiazepine group of tranquillizing drugs.

\section{Method}

During the period of inquiry all patients who were to undergo elective caesarean sections were premedicated with $10 \mathrm{mg}$. of diazepam by mouth on the night before operation and $10 \mathrm{mg}$. intramuscularly together with $0.6 \mathrm{mg}$. of atropine one hour preoperatively.

Patients requiring emergency section were used as the comparative group; the criterion for this group being operation during labour because of foetal or maternal distress. Some of these patients had received narcotics within six hours of operation, this being dictated purely by the requirements to produce pain relief during labour; the others had received only $0.6 \mathrm{mg}$. of atropine intramuscularly.

The patient population and the methods of assessment and inquiry were as used in our previous series (Wilson and Turner, 1969) apart from minor alterations in the questionary indicated by our previous results.

\section{Results}

Of the total 82 patients studied, the 17 who had received a narcotic within six hours of operation had no unpleasant recall of facts from the operation or of pain, but two of them could recall unpleasant dreams (Table I). This incidence of unpleasant recall, while higher than the figure in our previous series, must be considered in the light of the small number of patients and therefore the lesser likelihood of normal distribution in the current series compared with the previous one. Moreover, of the 39 who received atropine only preoperatively three $(7.6 \%)$ had definite recall of awareness during some part of the anaesthetic, while one patient-though having some recollection of intubation-was unable to recall anything else apart from an unpleasant dream. This total of four $(10 \cdot 2 \%)$

* Lecturer.

† Senior Registrar.

tenior Registrar. ary, Edinburgh 3 . 
with unpleasant recall in this group is considerably smaller than the proportion found in the previous series; but again the size of population (118 previously in the atropine group) must affect the distribution, and therefore the percentage obtained from the current series is, as in the narcotic group, less reliable than the previous series.

TABLE I.-Results of Present Series of 82 Patients Receiving a Narcotic, Diazepam, or Atropine alone, before Caesarean Section, Correlated with the Incidence of Awareness, Pain, and Types of Dream in each Group

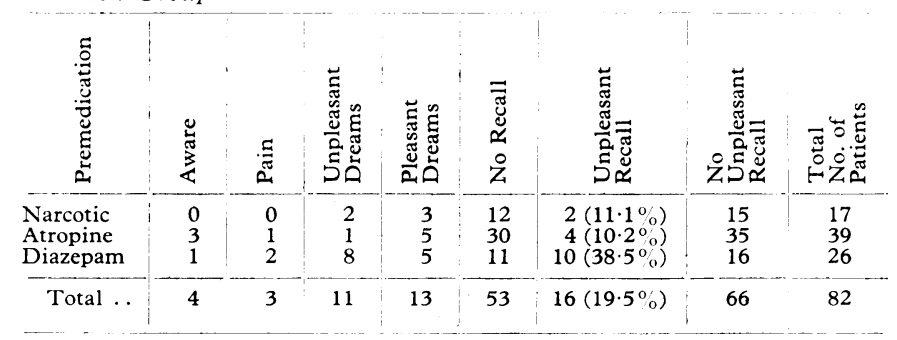

The most significant trend is seen in the group premedicated with diazepam. Of the total of 26 , one patient had recall of awareness with pain; one with pain recall alone; but eight with recall of unpleasant dreams. Thus the percentage of unpleasant recall in this group is $38.5 \%$ (10 patients). Though the figures for actual awareness and for pain recall are not significantly different from the atropine group, the degree of unpleasant dreaming is considerably increased. The difference between the groups receiving diazepam and atropine (Table I) shows that the likelihood of unpleasant recall is statistically significantly increased $\left(X^{3}=5 \cdot 7, P<0 \cdot 025\right)$ by the administration of diazepam.

\section{Discussion}

As we suggested in the conclusion to our previous paper (Wilson and Turner, 1969) we have investigated the effect of using one of the benzodiazepine group of tranquillizers (diazepam) as a premedicant in elective section in reducing the degree of unpleasant recall. Though this drug apparently, however, does not affect the degree of recall of facts from the period of anaesthesia or of recall of pain, it may be assumed that it considerably increases the likelihood of patients having unpleasant dreams during their anaesthetic. If the group of patients who received diazepam in this series is compared with the group who received atropine only in our previous series (Table II) a similar tendency to have unpleasant recall is demon-

TABLE II.-Incidence of Unpleasant Recall in Patients Receiving Atropine Premedication (previous series, Wilson and Turner, 1969) and in those Receiving Diazepam (present series)

\begin{tabular}{|c|c|c|c|}
\hline Premedication & $\underset{\text { Recall }}{\text { Unpleasant }}$ & $\begin{array}{l}\text { No Unpleasant } \\
\text { Recall }\end{array}$ & Total \\
\hline $\begin{array}{l}\text { Atropine (last series) } \\
\text { Diazepam } . . \quad \ldots\end{array}$ & $\begin{array}{l}25(21 \%) \\
10(38.5 \%)\end{array}$ & $\begin{array}{l}93 \\
16\end{array}$ & $\begin{array}{r}118 \\
26 \\
\end{array}$ \\
\hline Total $\quad$. & $35\left(24 \cdot 3_{0}^{\circ}\right)$ & 109 & 144 \\
\hline
\end{tabular}

Although there is a marked rise in the percentage of unpleasant recall in the diazepam group $\left(38.5^{\circ}\right)$ from the atropine group in the previous series $\left(21^{\circ}\right)$, the

strated in the diazepam group. Apart from the use of diazepam as the premedicant in this series, there were no other differences in the anaesthetic procedure between the two series. Consequently diazepam is probably to blame for the increase in unpleasant recall, and therefore is not a suitable premedicant for this type of anaesthesia. As a consequence of these results we have felt obliged to end the current investigation before we had intended. It must be made clear, however, that this trial was of a combination of oral and intramuscular diazepam premedication in anaesthesia for caesarean section. This, therefore, in no way casts doubts on the good results obtained by the use of this drug to produce amnesia when given intravenously (Kurland, 1968), or on its success as a premedicant for other general anaesthetic techniques (Gordon and Turner, 1969 ) or as an induction agent (Kyles, 1968). Of the many suggestions received after our previous paper, that of the use of intravenous hyoscine would appear to hold out greatest promise, and requires further investigation.

\section{REFERENCES}

Gordon, N. H., and Turner, D. J. (1969). British fournal of Anaesthesia, 41, 136

Kurland, P. (1968). British Dental fournal, 125, 302.

Kyles, J. R. (1968). Presidential Address to the Scottish Society of Anaesthetists, April.

Wilson, J., and Turner, D. J. (1969). British Medical fournal, 1, 280.

\title{
Pigmentation in Megaloblastic Anaemia Associated with Pregnancy and Lactation
}

\author{
N. BAUMSLAG, * M.B. ; J. METZ, $†$ M.D., M.C.PATH.
}

Summary : Generalized skin pigmentation in five $S$ African women with megaloblastic anaemia in the postnatal period was associated with low serum folate levels, as distinct from vitamin $B_{12}$ deficiency. It is suggested that the occurrence of pigmentation in both folate and vitamin $B_{12}$ deficiency may reflect a common abnormality of metabolism.

* South African Institute for Medical Research, Johannesburg. Present Address: Department of Environmental Health, University of Cincinnati Medical School, Cincinnati, Ohio 45219.

\section{Introduction}

Brownish pigmentation of the skin, which may be diffuse or blotchy, has long been recognized in pernicious anaemia (Wintrobe, 1967). Baker et al. (1963) suggested that this pigmentation may be specific for vitamin- $\mathrm{B}_{12}$ deficiency. These authors described deep brown or brownish black pigmentation of the skin, most pronounced in the hands and feet. In some cases there was patchy pigmentation over the palms and soles, and pigmentation also occurred in the buccal mucous membrane with spotty pigmentation of the tongue. The pigmentation 